\title{
$\mathrm{Q}$ 방법론을 이용한 예산 황새마을 조성사업의 갈등구조 분석
}

\author{
이재혁・박세진 ${ }^{*}$ 전수현・손용훈 ${ }^{* *}$ \\ 서울대학교 협동과정 조경학 박사과정 - ${ }^{*}$ 서울대학교 환경대학원 환경조경학과 •**서울대학교 환경대학원
}

\section{Conflict Structure Analysis on the Construction of stork Eco-Village in Yesangun Using Q methodology}

\author{
Lee, Jae-Hyuck • Park, Se-Jin • Jeon, Soo-Hyun • Son, Yong-Hoon ${ }^{* *}$ \\ Interdisciplinary Program in Landscape Architecture, Seoul National University \\ ${ }^{*}$ Dept. of Landscape Architecture, Graduate School of Environmental Studies, Seoul National University \\ ${ }^{* *}$ Assistant Professor, Graduate School of Environment Studies, Seoul National University
}

\begin{abstract}
Ecotourism has the potential to boost the energy of a village as it pays keen attention to the ecosystem and the residents of the village. It is empowered by participation of and cooperation among stakeholders who are closely involved in ecotourism. However, many of them express difficulty in striking a right balance between development and conservation with regard to promoting ecotourism. Against this backdrop, this research paper investigates the structure of conflict that the stakeholders, especially those in Stork Village in Yesan County, South Chungcheong Province of Korea, experience during the process of establishment of government-led ecotourism. In addition, this study examines the problems of government-led ecotourism model and how they can be addressed. To analyze conflict structure, this paper used Q methods and found out that the budget-related stakeholders are largely divided into four groups as who; a) complain about how business profits are distributed; b) secure profits by expanding programs; c) consider human settlement, and; d) broaden people's participation. The biggest contributor to the conflicts is found that compensation was given discriminately to different jurisdictions. The second finding is that residents became less cooperative when the financial compensation did not live up to their expectation. For instance, they would demand the tourism facility physically expanded, repeatedly complain about the process of the work, and even accuse the government of degrading ecosystem. In other words, unless the compromise is reached with the residents regarding financial compensation, it could be difficult to encourage their participation and develop as a program-oriented tour. Lastly, the tour program needs to induce voluntary participation of the residents and deliver proper information on ecosystem and natural resources so as to last as sustainable ecotourism. The success of ecotourism will be subject to the cooperation of stakeholders in a region, conservation of our fragile ecosystem, and realization of sustainable growth through sharing economic benefits. This study looks into the cause of the conflicts of ecotourism sites and their structure. If this paper can bring about cooperation of stakeholders, the management and operation of ecotourism sites would be more sustainable.
\end{abstract}

Key words : Eco-tourism, Stakeholder, Q methodology, Yesan stork Eco-village

\section{I. 연구 배경 및 목적}

2000년대 이후 우리나라에 등장한 생태관광(Eco

Corresponding Author, Son, Yong-Hoon

Tel : 02-880-8107

E-mail : Sonyh@snu.ac.kr tourism), 녹색관광(Green tourism) 등의 대안관광 (Alternative tourism)은 수익 창출을 목적으로 하는 일반 관광업과 달리 지역 환경의 보전 및 지역 재생의 수단으 로 인식되고 있다. 이에 농림부, 환경부, 문화체육관광부 등 각 부처는 생태관광에 국비를 지원하고 있으며, 지자 체에서도 큰 관심을 보이고 있다. 
하지만 이러한 기대와는 달리 생태관광지 조성현장에 서는 적지 않은 문제와 갈등이 일어나고 있다. 생태관광 지 조성사업에서 지역의 환경에 대한 고려나 경관에 대 한 배려가 충분히 이루어지지 않고 있는 문제도 있지만, 다른 관점에서는 생태관광 시행에 따른 지역주민에 대한 규제가 주민들의 지역이주를 결심하게 하기도 한다.

일반적으로 생태관광 사업의 초반에는 지역주민이 정 부가 제시한 생태관광 개발안에 찬성하지만, 조성과정에 서 나타난 다양한 갈등 속에서 주민들은 많은 불만을 토 로하게 된다. 기본적으로 생태관광은 지역 환경에 대한 보전과 함께 주민들의 삶에 대한 배려도 필요하다. 따라 서 조성과정, 운영과정에서 발생하는 갈등 구조를 분석 하고 해결책을 모색하는 것은 지속가능한 생태관광의 실 천에 있어서 중요한 과정이라고 하겠다.

국내에서는 생태관광에 대한 관심이 늘며 관련 연구 가 계속적으로 이어져왔다(김진·고동완,2011; 이호영·오 충현,2012; 김정민,2012). 하지만 많은 연구들은 생태성에 편중되어 있으며, GIS 등을 이용한 광역생태분석을 통한 전문가적 해석을 중심으로 생태관광지를 제안하고 있다.

이에 반해서 생태관광 조성과정에 있어서는 지역주민 등 이해당사자들의 의견을 파악하는 것도 중요하다 (Gurung, D. B. and R. W. Scholz,2008 García-Melón, M., et al.,2012; Graci, S.,2013; Hunter, W. C,2013; Wunder, S., 2000). Wunder, S.(2000)은 아마존 생태관광 문제들을 해 결하기 위해서는 지역 이해당사자들의 의견수렴과 참여 가 결정적으로 영향을 미치고 있음을 밝혀냈다. Gurung, D. B. and R. W. Scholz(2008)은 정부주도형 관광에 대한 전문가와 일반주민들의 인식차이를 시나리오로 비교분석 하여 일반주민들의 미시적 의견을 파악하였다. Hunter, W. C(2013)은 생태관광 조성과정에 대한 여러 이해당사 자들의 인식차이를 비교분석하였다. 또한 Graci, S.(2013) 는 생태관광 조성 단계별로 이해당사자의 인식차이를 비 교분석하여 각 단계별로 발생하는 문제와 해결방안을 제 안하였다. 그리고 García-Melón, M., et al.(2012)는 설문조 사를 통해서 생태관광의 세부 항목들에 대한 이해당사자 들의 선호도를 파악하였다. 이상의 연구들을 종합해보면 생태관광 조성과정에 나타나는 이해당사자들의 인식을 정량적인 방법과 정성적인 방법을 통해서 다양하게 분석 하고 있다. 지역사람들이 생태관광에 많은 관심을 갖고 관리한다면 생태관광은 생태적 민감성을 잘 지키며 경 제, 사회적 효과도 얻을 것이다(White, N. E., et al.,2013). 따라서 이해당사자들의 협력관계를 구축하는 것은 생태 관광의 발전에 꼭 필요하다(Coles, T.,2009). 그래서 많은 연구자들이 생태관광의 이해당사자들 사이에 갈등과 문 제를 연구하고 있다(Gurung, D. B. and R. W. Scholz,
2008; 조중현,2008).

이 연구의 목적은 생태관광 이해당사자를 대상으로 그들의 가치, 신념, 선호 등 주관적 속성을 분석하여, 생 태관광 조성과정에서 발생하는 이해관계자 간의 갈등 구 조를 파악하는 것이다. 구체적으로는 2012년 국내 황새 복원을 목표로 조성된 충청남도 예산군 황새마을을 대상 으로 생태관광을 진행하면서 나타나는 이해당사자들에게 발생하는 갈등의 형태를 파악하고, 갈등 주체 별로 구조 화하고 갈등 주체간의 관계를 파악하였다. 이를 통해서 향후 생태관광 사업의 추진에 있어서 주의해야 할 점들 을 고찰하였다.

\section{II. 연구방법}

본 연구의 공간적 범위는 2012년 국내 황새 복원을 목표로 환경부와 농림수산식품부, 문화재청 등 다양한 기관으로부터 약 180 억 원이라는 생태관광지 조성 자금 을 지원받은 충청남도 예산군 황새마을이다. 황새마을은 황새의 성공적인 야생 복귀를 통한 생태관광 인프라 구 축, 생태농업을 통한 지역농업의 활성화, 효율적인 고향 공원 시설 운영 등 다양한 생태관광 요소를 계획 하였으 나(예산군, 2012), 참여 전문가의 변경, 생태농업 보상에 대한 지역주민의 항의 등 이해당사자들의 갈등으로 인해 생태관광 추진에 난항을 겪고 있다(경향신문, 2013; 중도 일보, 2014; 충청투데이, 2012; YTN, 2012). 또한 아직 예 산 황새마을이 조성 중에 있으므로, 정부주도 생태관광 의 조성과정 중에 나타나는 문제점을 현장에서 확인할 수 있다.

본 연구에서는 생태관광지의 갈등 분석을 위한 연구 방법으로 $\mathrm{Q}$ 방법론을 사용하였다. Q 방법론은 인간의 주관성(subjectivity)을 과학적으로 측정하는 방법론으로, 정성적 방법론과 정량적 방법론의 결합된 형태를 뛴다 (Russell C. Hurd \& Steven R. Brown, 2004). Q 방법론은 1970 년대 정량적 연구방법론을 비판하며 등장하였다. 기 존 계량연구방법론은 연구자의 조작적 정의에 따라 가설 이 결정된다. 따라서 연구대상의 전체적인 면보다는 연 구자가 보려는 면을 보게 된다는 한계점을 지닌다. 또한 연구대상보다 연구방법론의 운영에 크게 좌우된다는 단 점도 있다(김순은, 2007).

이에 $\mathrm{Q}$ 방법론은 특정 주제나 현상에 대해 개인이 가 지고 있는 각기 다른 느낌, 가치, 믿음, 신념 등을 유형 별로 묶어 분석하는 방법론이다(국토연구원, 2010). 분석 과정에서 주관성을 측정하는 만큼 연구자가 선행해서 분 석 틀을 만들지 않고, 대상지에 대한 정성적인 연구를 
통해 진술문을 확보한 다음 정량적인 연구로 발전시킨다 (김순은, 2007). 따라서 $\mathrm{Q}$ 방법론은 양적 연구로 접근이 어려운 지역의 복잡한 갈등 문제를 객관적으로 분석하기 에 매우 유용하다(이순자·박형서, 2011).

본 연구는 충청남도 예산군 황새 권역단위 종합정비 사업 기본계획서(예산군, 2013)의 내용과 예비조사로 2013년 10월 9일 지역의 이해당사자 12명(공무원, 시목 리와 대리 마을이장, 사무장, 목사, 자연생태 해설사 양 성과정 교육자 등)의 인터뷰를 실시해 이해당사자들이 인식하는 여러 쟁점을 확인하고, 25 개의 $\mathrm{Q}$ 진술항목 $(\mathrm{Q}$ sheet)을 만들었다. 이후 본 조사로 2013년 10월 23일에 서 12 월 19 일에 걸쳐 $\mathrm{Q}$ 진술항목에 대한 설문조사를 진 행하고, $\mathrm{Q}$ 요인분석을 실시하였다. 설문대상자는 마을주 민과 관계공무원, 관광사업자를 포함하여 23명이다1). 이 러한 결과를 Excel 2013과 SPSS 21.0를 사용하여 분석하 였다. 본 연구의 흐름은 Figure 1 과 같다.

\section{Setting Research Objective}

Analysis of conflict structure in developing Stork Eco-Village

Overview of main issues in developing Stork Eco-Village

Literature investigation, Field study, Deep Interview

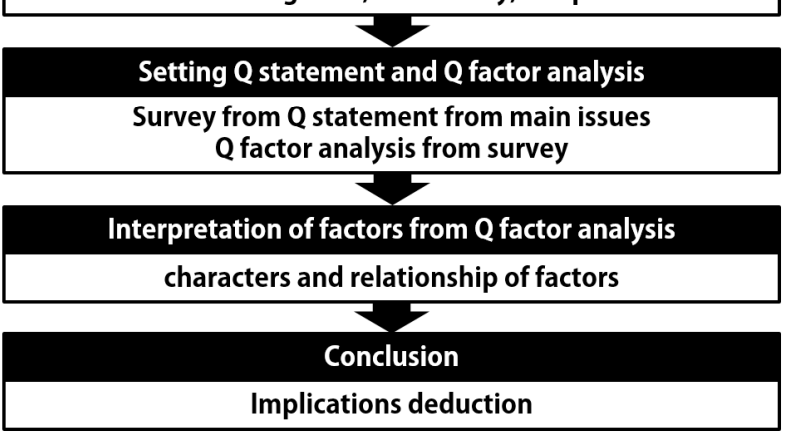

Figure 1. Process of the Research

\section{III. 연구 결가}

\section{1. 예산 황새마을 조성사업의 개요와 주요 쟁점}

2005년 황새복원센터는 자연방사를 통해 진정한 황새 복원을 이루기 위해 황새마을 조성을 제안하였다. 이에 문화재청이 주관하여 황새마을 조성사업을 전국 공모로 추진하였고, 심사를 거쳐 2009년 6월 예산군 광시면 대 리와 시목리 일대를 황새마을조성사업 대상지로 선정되 었다. 선정 이유는 예산군 광시면 시목리와 대리 일대는 살목지, 보강지 두 개의 저수지와 산림, 농경지, 하천을
가까이 하고 있어, 황새 서식에 적합한 환경이라는 점이 크게 작용했다(Figure 2 참조).

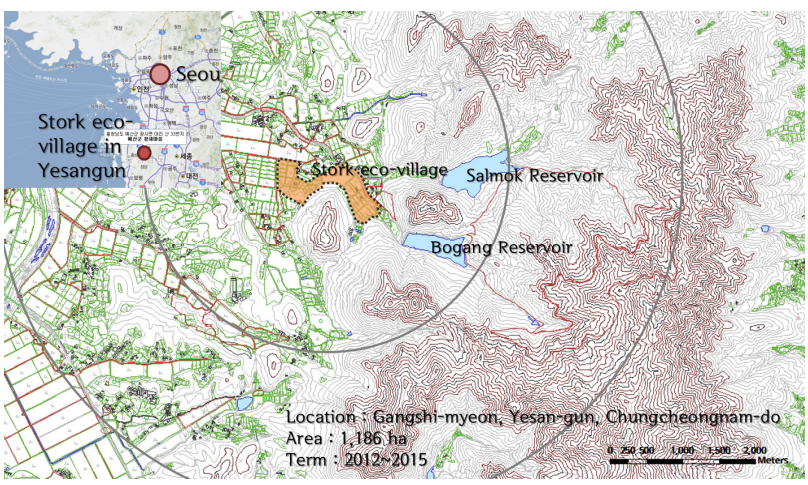

Figure 2. Location of Yesan Stork Eco-village

하지만 황새마을로 선정 후, 조성사업 과정 전반에 다 양한 문제와 갈등이 일어나게 되었다. 본 연구에서는 충 청남도 예산군 황새 권역단위 종합정비사업 기본계획서 (예산군, 2013)의 내용과 2013년 10월 9일 심층인터뷰의 내용을 통해 갈등 유형을 6가지 항목(시설배치, 교육 및 프로그램, 생태, 거버넌스, 경제, 기타)으로 정리하였다.

시설배치를 보면, 대리에 많은 생태관광시설이 조성되 어 대리 주민들이 보상을 많이 받은 반면, 인접한 시목 리와 가덕리에는 농경지가 많아 시목리, 가덕리 주민들 에게는 생태농업의 책임이 많이 주어진 상황이다(Figure 3 참조). 즉, 시설조성 과정에서 보상과 책임이 행정구역 에 따라 확연하게 나눠져 보상은 대리에, 의무와 책임은 시목리와 가덕리에 상대적으로 많이 주어져 있으며, 이

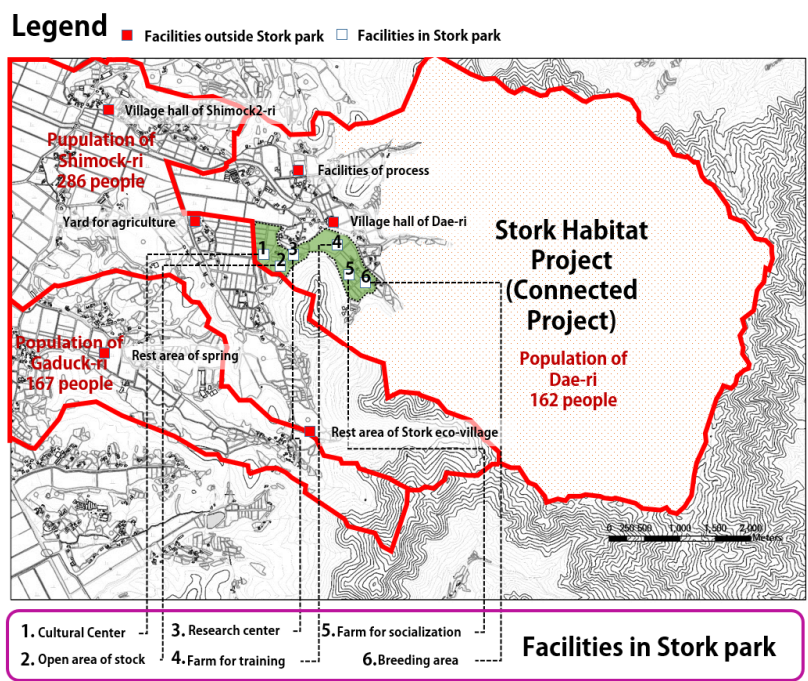

Figure 3. Map of Stork Eco-village Project Areas 


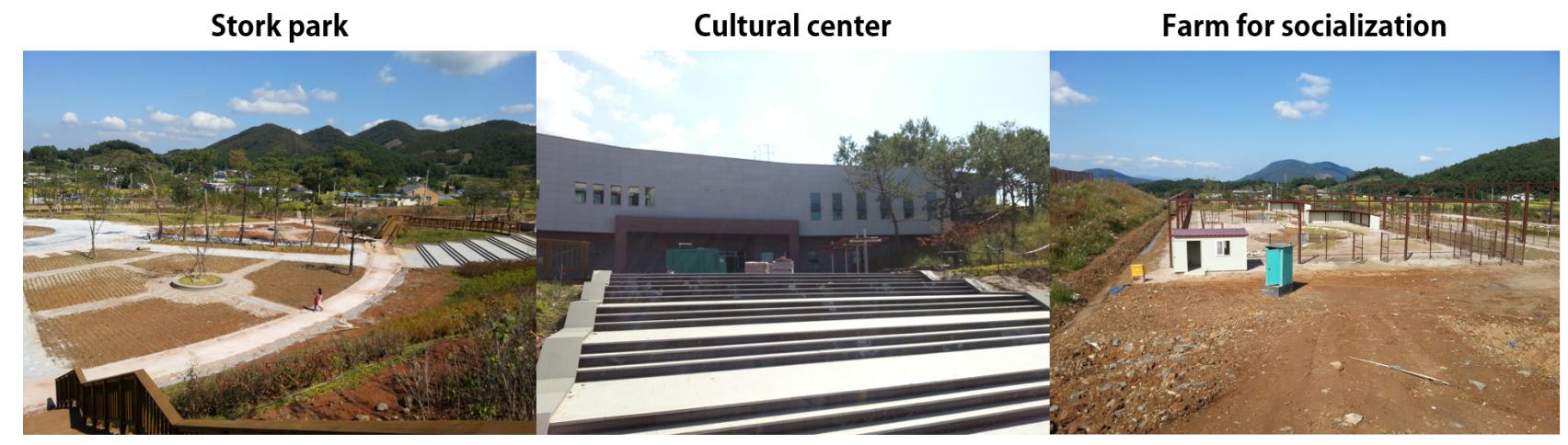

Figure 4. Facilities in Stork Eco-village Under Construction

는 주민간의 갈등으로 이어지고 있다.

교육 및 프로그램 면에서 보면, 아직 상당수 주민들이 농약을 안 쓰면 수확량이 준다고 생각하고 있을 정도로 생태농업에 대한 방법을 모르고 실천을 꺼려하고 있다. 그리고 보다 많은 교육과정을 통해 생태농업 기술을 배 우길 원하고 있다. 현재 유일한 생태농업교육은 공주대 학교 예산캠퍼스의 '자연생태 해설사 양성과정'이다. 하 지만 이 과정은 황새마을을 위해 특화된 교육과정이 아 니고, 황새마을에 대해서는 특강으로만 구성되어 있어 주민교육이 상당히 부족한 상황이다.

생태적인 측면에서 보면, 현재까지도 몇 농가에서 농 약이 검출된다는 점이 큰 문제이다. 그리고 황새가 날아 가지 않도록 날개깃을 제거하는 것에 대해서도 의견이 분분하다. 보육시설 측은 이미 상당수 동물원에서는 날 개깃 제거를 행하고 있다며 날개깃은 다시 자라나기 때 문에 잘라도 상관없다는 태도를 보이고 있다. 반면 조류 보호협회 홍성군지회장은 철새인 황새의 날개깃 제거는 명백한 천연기념물 학대라고 주장하고 있다(경향신문, 2013년 7월 25일자). 황새 배설물도 갈등을 유발하는 문 제이다. 황새 배설물은 강한 산성으로 많은 식물을 고사 시킬 수 있는 위력이 있다. 이에 주민들은 농작물과 인 체에 유해하지 않을까 걱정을 하고 있었다.

거버넌스 측면에서 보면, 행정구역에 따른 차등 보상 으로 인해서 황새마을 협의체 안에서도 각종 갈등이 유 발되고 있다. 시목리와 가덕리의 마을 지도자들은 생태 농업을 의무적으로 해야 하며, 황새 배설물은 자신들이 다 치우고 있지만, 주요 혜택은 대리가 다 받아간다고 생각하고 있다. 따라서 향후 본 사업에 관한 행사에도 크게 협조하지 않겠다는 입장이다. 또한 조성과정에서 배치된 전문가에 대해서도 상당수는 불만을 갖고 있었다.

경제적 문제로는 현재 유기농 쌀을 수매하고 있는 풀
무생협이 판로가 없다는 이유로 2014년부터는 예산 지 역의 유기농 쌀을 구매할 수 없다는 입장을 밝혀왔다. 2014년부터 유기농 쌀을 수매할 곳이 없다는 것이 큰 문제이다.

그 외에도, 개발이 중단된 공터와 쌍둥이 저수지와 연 계에 대한 문제도 쟁점 사항이다. 황새마을이 조성되며 주민들은 예산 청소년 수련마을 뒤 개발이 중단된 공터 도 연계하여 개발해서 마을의 골칫덩이 문제를 해결하길 원하고 있다. 하지만 공무원과 연구자들은 사업성이 맞 지 않아 반대하고 있다. 또한 황새공원 인근의 쌍둥이 저수지(살목지, 보강지)와 연계된 개발에 대해서도 의견 이 다르다. 주민들 중에는 쌍둥이 저수지가 훼손될까 걱 정하여 연계를 반대하는 사람도 있지만, 저수지와 연계 된 개발을 통해 개발 시너지 효과를 기대하는 사람들도 있다.

이와 같은 이유로 생태관광을 추진함에 있어서 황새 마을에는 많은 갈등이 유발되었고, 이를 해결하고자 4번 의 추진점검과 5 번의 회의를 진행하게 되었다.

\section{2. $Q$ 진술문 추출과 $Q$ 요인분석}

충청남도 예산군 황새 권역단위 종합정비사업 기본계 획서(예산군, 2013)와 예비조사의 인터뷰로부터 정리된 예산 황새마을 조성과정에 나타난 쟁점들을 토대로 25 개 $\mathrm{Q}$ 진술문을 도출하였다. 크게 내용별로 시설배치, 교육 및 프로그램, 생태, 거버넌스, 경제, 기타라는 6개 유형으 로 구분하였다.

총 25 개 $\mathrm{Q}$ 진술문 각각에 대해 총 23 명을 대상으로 2013년 10월 23일에서 12월 19일까지 설문조사를 실행 하였다. 중요 인물의 선정은 회의록에 참여한 주요 인물 과 사전에 이루어진 심층인터뷰 때 추천된 인물들로, 다 
음의 이해당사자들을 포함하였다. 첫 번째 이해당사자는 공무원이다. 공무원은 예산 황새마을사업에서 관의 입장 을 대변하고 있다. 두 번째 이해당사자들은 시목리와 대 리 지역주민이다. 이들은 황새마을사업을 통해 지역 활 성화를 원하고 있었다. 세 번째 이해당사자들은 전문가 (연구원) 및 시공업자(공사소장)들이다. 이 외에도 황새 마을사업에 관여하는 자(목사 등)를 포함시켰다.

이렇게 주요 이해당사자들을 대상으로 진행한 $\mathrm{Q}$ 요인 분석 결과가 Table 2이다. 분석결과 고유치(eigen value) 가 1 이상인 항목은 8 개 있었으며, 해석이 용이한 상위 4 개 요인으로 분류하여 분석하였다.

Table 1. Main issues from Q statement

\begin{tabular}{|c|c|c|}
\hline No. & Category & Q Statement \\
\hline 1 & \multirow{8}{*}{$\begin{array}{l}\text { Disposition of } \\
\text { facilities }\end{array}$} & Stork eco-village facilities should be allocated. \\
\hline 2 & & $\begin{array}{l}\text { Stork inhabitation facilities are too far from } \\
\text { eco-stork park. }\end{array}$ \\
\hline 3 & & $\begin{array}{l}\text { Resident center(Offiice) should be built first for } \\
\text { resident participation. }\end{array}$ \\
\hline 4 & & Size of Stork park is proper for tourists to use. \\
\hline 5 & & $\begin{array}{l}\text { Stock eco-village facilities and parks are well } \\
\text { positioned. }\end{array}$ \\
\hline 6 & & Farm facilities for storks are proper to raise them. \\
\hline 7 & & $\begin{array}{l}\text { Size of Facilities in Eco-stork village are proper } \\
\text { for local residents to manage. }\end{array}$ \\
\hline 8 & & $\begin{array}{l}\text { Land purchase should be done although there is } \\
\text { compulsion. }\end{array}$ \\
\hline 9 & \multirow{2}{*}{$\begin{array}{l}\text { Education \& } \\
\text { program }\end{array}$} & $\begin{array}{l}\text { Education for local residents about ecological } \\
\text { farming, eco-stork village is well conducted. }\end{array}$ \\
\hline 10 & & $\begin{array}{l}\text { Program development is more important that } \\
\text { facility development. }\end{array}$ \\
\hline 11 & \multirow{3}{*}{ Ecology } & There will be damages because of stool of stork. \\
\hline 12 & & Remove of flap is ecologically not bad. \\
\hline 13 & & $\begin{array}{l}\text { Ecological Agriculture will let Stock live in Good } \\
\text { Environment. }\end{array}$ \\
\hline 14 & \multirow{5}{*}{ Governance } & $\begin{array}{l}\text { Additional manpower is needed as professionals } \\
\text { and managers. }\end{array}$ \\
\hline 15 & & Eco-stock village should be led by government. \\
\hline 16 & & $\begin{array}{l}\text { Local residents should participate in ecological } \\
\text { farming. }\end{array}$ \\
\hline 17 & & $\begin{array}{l}\text { Professor. Park should continuously be main reader } \\
\text { role as an expert in developing eco-stork village. }\end{array}$ \\
\hline 18 & & $\begin{array}{l}\text { Eco-stork village project is not for local residents. } \\
\text { It is just for tourists. }\end{array}$ \\
\hline 19 & \multirow{4}{*}{ Economy } & $\begin{array}{l}\text { Residents profit will be increased thanks to } \\
\text { ecological agriculture. }\end{array}$ \\
\hline 20 & & $\begin{array}{l}\text { Great money (almost } 16 \text { million dollars) supported } \\
\text { from government is well used. }\end{array}$ \\
\hline 21 & & $\begin{array}{l}\text { Compensation expenses from purchase of harvest } \\
\text { by government are distributed fairly. }\end{array}$ \\
\hline 22 & & $\begin{array}{l}\text { Government support is proper for ecological } \\
\text { agriculture. }\end{array}$ \\
\hline 23 & \multirow{3}{*}{ Et cetera(etc.) } & $\begin{array}{l}\text { Eco-stock village project should be related with } \\
\text { suspended building area. }\end{array}$ \\
\hline 24 & & $\begin{array}{l}\text { Linked development with Twins reservoir is } \\
\text { needed. }\end{array}$ \\
\hline 25 & & Development connected with slow city is needed. \\
\hline
\end{tabular}

Table 2. Q Factor Analysis Result

\begin{tabular}{|c|c|c|c|c|}
\hline Sort & Factor 1 & Factor 2 & Factor 3 & Factor 4 \\
\hline Resident of Shimock-ri & .746 & .210 & .095 & -.294 \\
\hline Leader & .736 & .274 & .098 & .030 \\
\hline Resident of Shimock-ri & .730 & -.224 & -.205 & -.234 \\
\hline Leader of Shimock-ri & .702 & -.032 & .429 & .229 \\
\hline Leader of Shimock-ri & .690 & .203 & .102 & .328 \\
\hline Resident of Shimock-ri & .635 & .060 & .225 & .538 \\
\hline Resident of Shimock-ri & .613 & .012 & .391 & .173 \\
\hline Resident of Shimock-ri & .578 & -.097 & .430 & -.143 \\
\hline Researcher & -.055 & .775 & .045 & .139 \\
\hline Leader of Dae-ri & .262 & .759 & .080 & .119 \\
\hline Leader of Dae-ri & -294 & .731 & .138 & .066 \\
\hline Leader of Dae-ri & .126 & .695 & -.557 & -.069 \\
\hline Leader of Dae-ri & .226 & .633 & .212 & .231 \\
\hline Resident of Dae-ri & .257 & .504 & .100 & -.273 \\
\hline Manager of Construction & .041 & .502 & -.391 & -.024 \\
\hline Resident of Shimock-ri & .320 & .183 & .748 & -.056 \\
\hline Officer(Other Department) & .051 & .009 & .586 & .335 \\
\hline Leader of Shimock-ri & .041 & -.013 & .579 & -.418 \\
\hline Resident of Shimock-ri & .270 & .108 & .579 & .041 \\
\hline Resident of Shimock-ri & .142 & .167 & .189 & .641 \\
\hline Resident of Shimock-ri & .021 & .029 & .028 & .477 \\
\hline Minister & -.096 & .376 & -.231 & .471 \\
\hline Local Officer & .181 & .304 & .277 & -.435 \\
\hline Eigen Value & 4.247 & 3.634 & 2.930 & 2.156 \\
\hline Variance Explanation & 18.5 & 15.8 & 12.7 & 9.4 \\
\hline Cumulative Variance Explanation & 18.5 & 34.2 & 47.0 & 56.4 \\
\hline
\end{tabular}

\section{3. $Q$ 분석을 통해 나타난 요인과 해당 군집별 특성}

\section{1) 요인 1 : 사업이익 분배에 대한 불만}

Table 3은 사업이익 분배에 대한 불만 요인에 대한 $\mathrm{z}$ value가 높은 응답자의 성별, 나이, 직업, 주소, 거주기간 등의 속성을 정리한 것이며, Table 4는 그룹의 $\mathrm{Q}$ 진술문 에 대한 $\mathrm{Z}$ value의 절대값이 1 이상 값을 정리한 것이다. 이를 통해서 요인 1 을 중시하는 사람들 그룹의 특성과 사업에 대한 인식을 파악할 수 있다. 요인 1 의 값이 높 은 사람들의 군집은 오랜 기간 이 지역에 살고 있었던 시목리 및 인근 주민들이 해당되었다. 이들은 대리로 들 어가는 길목인 시목리에 거주하며, 황새마을 생태농업 등에 대한 책임과 희생은 많지만, 상대적으로 대리에 비 해 이익분배에 있어 불만을 가지고 있다. 이들은 연계개 발 및 시설의 분산 배치에 관한 진술문을 선호할 뿐 아 니라 수매과정 등 이익 분배에도 높은 관심을 보였다. 
Table 3. A Group who complains about profit distribution

\begin{tabular}{c|c|c|c|c|c|c}
\hline Sort & Z Value & Sex & Age & Occupation & Address & Residence Period \\
\hline Resident of Shimock-ri & $\underline{\mathbf{. 7 4 6}}$ & Man & Sixty & Agriculture & Shimock-ri & over 10 year \\
\hline Leader & $\underline{\mathbf{. 7 3 6}}$ & Man & Sixty & Agriculture & Gwangshisok-ri & over 10 year \\
\hline Resident of Shimock-ri & $\underline{\mathbf{. 7 3 0}}$ & Woman & Fifty & Agriculture & Shimock-ri & over 10 year \\
\hline Leader of Shimock-ri & $\underline{\mathbf{. 7 0 2}}$ & Man & Fifty & Agriculture & Shimock-ri & over 10 year \\
\hline Leader of Shimock-ri & $\underline{\mathbf{. 6 9 0}}$ & Man & Sixty & Agriculture & Shimock-ri & $2-5$ year \\
\hline Resident of Shimock-ri & $\underline{\mathbf{. 6 3 5}}$ & Man & Fifty & Agriculture & Shimock-ri & over 10 year \\
\hline Resident of Shimock-ri & $\mathbf{. 6 1 3}$ & Woman & Fifty & Agriculture & Shimock-ri & over 10 year \\
\hline Resident of Shimock-ri & $\underline{\mathbf{. 5 7 8}}$ & Man & Sixty & Agriculture & Shimock-ri & over 10 year \\
\hline
\end{tabular}

Table 4. Q statements of the group who complains about profit distribution

\begin{tabular}{c|c|c}
\hline No. & Q Statement & Z Value \\
\hline 1 & Stork eco-village facilities should be allocated & 2.161 \\
\hline 24 & Linked development with Twins reservoir is needed & 1.851 \\
\hline 14 & Additional manpower is needed as professionals and managers & 1.285 \\
\hline 11 & There will be damages because of stool of stork & 1.008 \\
\hline 2 & Stork inhabitation facilities are too far from eco-stork park & -1.245 \\
\hline 9 & Education for local residents about ecological farming, eco-stork village is well conducted & -1.487 \\
\hline 21 & Compensation expenses from purchase of harvest by government are distributed fairly & -2.010 \\
\hline
\end{tabular}

주민교육 홍보에 대해서도 불만이 많았다. 이들은 황 새마을 사업을 더욱 광역사업으로 진행하여 사업으로 파 생되는 이익분배에 있어서 공평성을 확보하기를 원하고 있다.

\section{2) 요인 2 : 프로그램을 통한 수익보장}

Table 5는 프로그램을 통한 수익보장 요인에 대한 $\mathrm{z}$ value가 높은 응답자의 성별, 나이, 직업, 주소, 거주기간 등의 속성을 정리한 것이며, Table 6 는 그룹의 $\mathrm{Q}$ 진술문

Table 5. A group securing profits from program operation

\begin{tabular}{|c|c|c|c|c|c|c|}
\hline Sort & Z Value & Sex & Age & Occupation & Address & Residence Period \\
\hline Researcher & .775 & Woman & Thirty & Specialist & Hongsung-gun & before 1 year \\
\hline Leader of Dae-ri & .759 & Man & Fifty & Agriculture & Dae-ri & over 10 year \\
\hline Leader of Dae-ri & .731 & Man & Fifty & Agriculture & Dae-ri & over 10 year \\
\hline Leader of Dae-ri & .695 & Man & Fifty & Specialist & Dae-ri & $1-2$ year \\
\hline Leader of Dae-ri & .633 & Woman & Fifty & Agriculture & Dae-ri & over 10 year \\
\hline Resident of Dae-ri & .504 & Man & Sixty & Agriculture & Dae-ri & over 10 year \\
\hline Manager of onstruction & .502 & Man & Fifty & Agriculture & Dae-ri & before 1 year \\
\hline
\end{tabular}

Table 6. Q statements of the group securing profits from program operation

\begin{tabular}{c|c|c}
\hline No. & Q Statement & Z Value \\
\hline 10 & Program development is more important that facility development & 2.200 \\
\hline 14 & Additional manpower is needed as professionals and managers & 1.456 \\
\hline 5 & Stock eco-village facilities and parks are well positioned & 1.326 \\
\hline 9 & Education for local residents about ecological farming, eco-stocl village is well conducted & 1.069 \\
\hline 8 & Land purchase should be done although there is compulsion & -1.048 \\
\hline 2 & Stock inhabitation facilities are too far from eco-stock park \\
\hline 11 & There will be damages because of stool of stork & -1.731 \\
\hline
\end{tabular}


에 대한 $\mathrm{Z}$ value의 절대값이 1 이상 값을 정리한 것이다. 요인 2의 값이 높은 사람들의 군집은 주로 황새마을 조 성의 실질적 주체와 사업이 집중된 대리지역의 주민들이

이 그룹에 해당되었다. 이 그룹은 더 이상의 시설 확 충보다는 흥미 있는 프로그램을 개발하여 생태관광이 활 성화 될 수 있도록 전문가 및 실행 인력에 대한 투자를 요구하고 있다. 지금까지 황새마을시설 및 공원들은 적 절하다고 생각하였다. 또한 황새 배설물 등 대리 외 주 변 농가에 주는 피해에 대해서는 큰 관심을 가지고 있지 않았다.

\section{3) 요인 3 : 정주환경 고려}

Table 7는 정주환경 고려 요인에 대한 $\mathrm{z}$ value가 높은 응답자의 성별, 나이, 직업, 주소, 거주기간 등의 속성을 정리한 것이며, Table 8 은 그룹의 $\mathrm{Q}$ 진술문에 대한 $\mathrm{Z}$ value의 절대값이 1 이상 값을 정리한 것이다. 요인 3 의 값이 높은 사람들의 군집은 마을에 오랜 살았던 시목리 의 일반주민들이 주로 해당되었다. 이들은 마을의 리더 는 아니지만 오랜 기간 동안 이 지역에 살았던 사람들로 황새마을 조성사업을 통해 정주공간으로서의 변화에 대 해 소극적이지만 염려하고 있었다. 이들은 마을의 골칫 덩어리였던 개발 중단된 공터를 해결하길 원하고 있었 다. 또한 쌍둥이 저수지의 개발로 인한 훼손, 황새 날갯 짓에 대해서는 염려하는 인식을 나타냈다. 문제점을 인 식하지만 직접적인 개선의지 보다는 관주도의 황새마을 운영을 원했다.

\section{4) 요인 4 : 주민참여 확대}

Table 9는 주민참여 확대 요인에 대한 $\mathrm{z}$ value가 높은 응답자의 성별, 나이, 직업, 주소, 거주기간 등의 속성을

Table 7. A group showing passive affection for a region

\begin{tabular}{c|c|c|c|c|c}
\hline Sort & Z Value & SEX & AGE & Occupation & Residence Period \\
\hline Resident of Shimock-ri & $\underline{\mathbf{. 7 4 8}}$ & Man & Sixty & Agriculture & Shimock-ri \\
\hline $\begin{array}{c}\text { Officer(Living in Shimock-ri) } \\
\text { Former president in women's } \\
\text { society }\end{array}$ & $\underline{\mathbf{. 5 8 6}}$ & Man & Forty & Office Worker & Shimock-ri \\
\hline \begin{tabular}{c} 
Resident of Shimock-ri \\
\hline
\end{tabular} & $\underline{\mathbf{. 5 7 9}}$ & Woman & Sixty & Agriculture & Shimock-ri \\
\hline
\end{tabular}

Table 8. Q Statements of the group showing passive affection for a region

\begin{tabular}{c|c|c}
\hline No. & Q Statement & Z Value \\
\hline 23 & Eco-stock village project should be related with suspended building area \\
\hline 10 & Program development is more important that facility development & 1.658 \\
\hline 15 & Eco-stock village should be led by government & 1.403 \\
\hline 3 & Resident center(Offiice) should be built first for resident participation & 1.000 \\
\hline 22 & Government support is proper for ecological agriculture & -1.108 \\
\hline 19 & Residents profit will be increased thanks to ecological agriculture \\
\hline 21 & Remove of flap is ecologically not bad \\
\hline 24 & Linked development with Twins reservoir is needed \\
\hline
\end{tabular}

Table 9. A group who wants expansion of the participation of local residents

\begin{tabular}{c|c|c|c|c|c}
\hline Sort & Z Value & Sex & Age & Occupation & Residence Period \\
\hline Resident of Shimock-ri & $\underline{\mathbf{. 6 4 1}}$ & Man & Fifty & Office Worker & Shimock-ri \\
\hline Resident of Shimock-ri & $\underline{\mathbf{4 7 7}}$ & Man & Sixty & Agriculture & Shimock-ri \\
\hline Pastor & $\underline{\mathbf{4 7 1}}$ & Man & Forty & Ministry & Shimock-ri \\
\hline
\end{tabular}


이재혁 · 박세진 · 전수현 · 손용훈

Table 10. Q statements of the group who wants expansion of the participation of local residents

\begin{tabular}{c|c|c}
\hline No. & Q Statement & Z Value \\
\hline 23 & Eco-stock village project should be related with suspended building area & 2.154 \\
\hline 22 & Government Support is proper for Ecological Agriculture & 1.316 \\
\hline 5 & Stock Eco-village Facilities and Parks are well positioned & 1.149 \\
\hline 24 & Link Development with Twins Reservoir is needed & 1.020 \\
\hline 13 & Ecological Agriculture will let Stock live in Good Environment & -1.061 \\
\hline 8 & Land Purchase should be done although there is compulsion & -1.504 \\
\hline 15 & Eco-Stock Village should be led by Government & -1.845 \\
\hline 9 & Education for Local Residents about Ecological Farming, Eco-stock Village is well conducted & -1.98531 \\
\hline
\end{tabular}

정리한 것이며, Table 10 은 그룹의 $\mathrm{Q}$ 진술문에 대한 $\mathrm{Z}$ value의 절대값이 1 이상 값을 정리한 것이다. 요인 4 의 값이 높은 사람들의 군집은 시목리 주민과 교회 목사 등 이 해당되었다. 이들은 마을의 현안에 관심도 많고, 정부 에 대한 여러 정책에 대해서도 비교적 긍정적이었다. 그 러나 관주도형 사업에 대해서는 비판적 인식을 가지고 있고 주민주도형으로 마을을 개발해야 한다고 하며 이를 위해서는 주민교육이 필요하다고 하였다. 이는 향후 이 사업이 주민주도로 이루어지길 바라며, 여러 사업을 보
다 현지주민들에게도 도움이 될 수 있도록 이끌려는 의 식이 보인다.

\section{5) 주요 군집별 태도와 상호 분석}

분석결과를 바탕으로 군집간 특성을 비교한 것이 Table 11이며, 이로부터 파악된 상호관계를 Figure 5와 같이 도식화하였다. 군집 1 과 군집 3 은 물리적 시설의 확 충을 원하고 있는 반면, 군집 2 , 군집4는 프로그램에 더욱 관심이 많았다. 군집1(시목리주민), 군집2(대리주민)은 사 업이익에 대해서 적극성을 띄는 반면, 군집 3 , 군집4는 상

Table 11. Comparison by groups from Q method

\begin{tabular}{|c|c|c|c|c|}
\hline Cluster name & $\begin{array}{l}\text { Cluster } 1 \text { : Cluster who has } \\
\text { dissatisfaction about profit } \\
\text { distribution }\end{array}$ & $\begin{array}{l}\text { Cluster } 2 \text { : Cluster who wants } \\
\text { more profit from various } \\
\text { program }\end{array}$ & $\begin{array}{l}\text { Cluster } 3 \text { : Cluster has } \\
\text { defensive place attachment }\end{array}$ & $\begin{array}{c}\text { Cluster } 4 \text { : Cluster who is in } \\
\text { expanding local residents' } \\
\text { participation }\end{array}$ \\
\hline $\begin{array}{c}\text { Main agent } \\
\text { (No. of people) }\end{array}$ & $\begin{array}{c}\text { Resident of Shimock-ri } \\
\text { people) }\end{array}$ & $\begin{array}{l}\text { Researcher, } \\
\text { Manager of Construction, } \\
\text { Resident of Dae-ri } \\
\text { (7 people) }\end{array}$ & $\begin{array}{l}\text { Resident of Shimock-ri } \\
\text { (4 people) }\end{array}$ & $\begin{array}{c}\text { Resident of Shimock-ri, } \\
\text { Pastor } \\
\text { (3 people })\end{array}$ \\
\hline Disposition of facilities & $\begin{array}{l}\text { Asking Distributed arrangement } \\
\text { and additional facilities }\end{array}$ & $\begin{array}{l}\text { Satisfying with arrangement } \\
\text { nowadays }\end{array}$ & $\begin{array}{l}\text { Asking additional facilities for } \\
\text { residents }\end{array}$ & $\begin{array}{l}\text { Satisfying but asking no } \\
\text { compulsion in development }\end{array}$ \\
\hline Education \& program & $\begin{array}{l}\text { Not satisfying with resident } \\
\text { education \& } \\
\text { asking facility development } \\
\text { rather than program } \\
\text { development }\end{array}$ & $\begin{array}{l}\text { Satisfying with education } \\
\text { nowadays \& wanting more } \\
\text { program }\end{array}$ & $\begin{array}{l}\text { Satisfying with education } \\
\text { nowadays \& wanting more } \\
\text { Program }\end{array}$ & $\begin{array}{c}\text { Not satisfying with resident } \\
\text { education }\end{array}$ \\
\hline Ecology & $\begin{array}{l}\text { Worrying about habitat of } \\
\text { storks, stool, remove of flap }\end{array}$ & $\begin{array}{l}\text { Not worry about stool of eco } \\
\text { stork \& worry about habitat of } \\
\text { storks, stool }\end{array}$ & $\begin{array}{c}\text { Worry about habitat of storks, } \\
\text { stool }\end{array}$ & $\begin{array}{l}\text { Worrying about habitat of } \\
\text { storks, stool, remove of flap }\end{array}$ \\
\hline Governance & $\begin{array}{l}\text { Asking more manpower and } \\
\text { government-led eco-tourism }\end{array}$ & Asking more manpower & $\begin{array}{l}\text { No needs for manpower } \\
\text { and asking government-led } \\
\text { eco-tourism }\end{array}$ & $\begin{array}{l}\text { Asking more manpower and } \\
\text { resident-led ecotourism }\end{array}$ \\
\hline Economy & $\begin{array}{l}\text { Negative for distribution of } \\
\text { support fund }\end{array}$ & $\begin{array}{l}\text { Positive for distribution of } \\
\text { support fund }\end{array}$ & $\begin{array}{l}\text { Negative for distribution of } \\
\text { support fund and future profit }\end{array}$ & $\begin{array}{l}\text { Negative for distribution of } \\
\text { support fund but positive for } \\
\text { future profit }\end{array}$ \\
\hline Et cetera(etc.) & $\begin{array}{l}\text { Asking linkage with two } \\
\text { reservoir for tourism } \\
\text { development }\end{array}$ & $\begin{array}{l}\text { Asking linkage with two } \\
\text { reservoir for tourism } \\
\text { development }\end{array}$ & $\begin{array}{l}\text { Not asking with two reservoir } \\
\text { for preservation }\end{array}$ & $\begin{array}{l}\text { Asking linkage with all other } \\
\text { possible tourism attraction }\end{array}$ \\
\hline
\end{tabular}




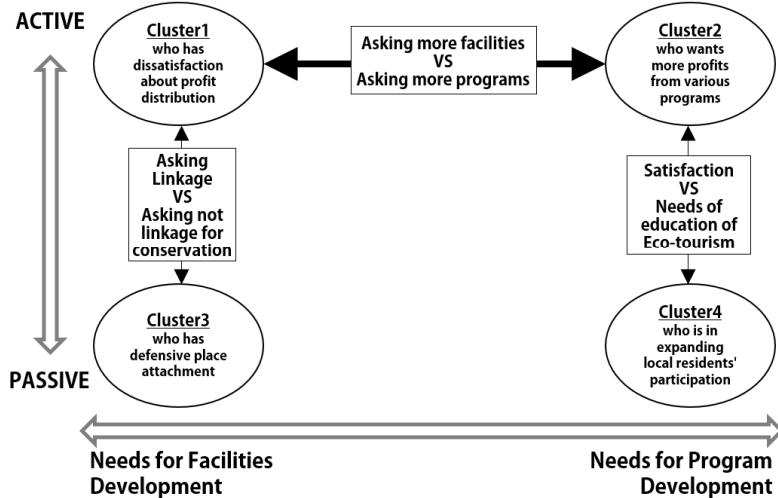

Figure 5. Conflict structure of groups divided by Q methodology

대적으로 소극성을 띄었다. 즉 갈등의 핵심에는 소수이 익에 민감한 군집1과 군집2에 있었고, 군집3과 군집4는 이를 방관적으로 보는 형태인 것을 확인할 수 있었다.

세부적으로 살펴보면 군집1은 시설의 추가분산 배치 를 통해 정부지원을 더 나누어 받기를 원하였다. 군집1 에 비해, 군집 2 는 충분한 보상을 받았다고 인식하여 프 로그램을 통한 관광수익창출에 관심이 더 많았다. 군집1 은 개발을 위해 쌍둥이 저수지 연계사업에 찬성하였으 나, 군집 3 은 정주환경으로서 대상지를 인식하여 쌍둥이 저수지 연계개발에 반대하였다. 군집1은 지원을 더 받는 관주도 생태관광개발을 원하였으나, 군집4는 주민선호방 식을 더 원하였다.

군집2의 경우, 기존 주민교육과 소득분배에도 만족하 였다. 그러나 군집 2 와는 다르게, 군집 3 은 소득분배에 불 만족하였고, 군집4는 주민교육에 불만족하였다. 군집 3 은 타지역 추가인력에 대해 배타적이었으나 군집 4 는 추가인 력에 대해 긍정적이었다. 이렇게 각자의 세부적 이해차 이를 확인할 수 있었다.

예산 황새마을 조성과정에서 나타난 이슈들은 다양한 문제로 보이지만 크게는 이익의 분배에 불만인 군집과 만족한 군집이 가장 큰 갈등이 있었고, 정주환경과 주민 참여의 문제도 나타났다.

\section{IV. 결론 및 고찰}

본 연구는 예산 황새마을 사례로 정성과 정량적인 측 면을 모두 고려할 수 있는 $\mathrm{Q}$ 방법론을 사용하여 정부주 도 생태관광 사업에 관련한 지역 내 이해관계자 간의 갈 등구조를 파악하였다. 이를 통해서 다음의 시사점을 도 출하였다.
첫째, 행정구역에 따라 생태관광계획을 하는 것이 바 람직하지 않다는 점이다. 예산 황새마을을 $\mathrm{Q}$ 방법론으로 분석해본 결과, 수혜지역인 대리주민들과 비수혜지역인 시목리 주민들 사이 강한 인식차이를 확인할 수 있었다. 이렇게 된 이유는 사업지역의 황새서식지로서 실제적인 대상지가 두 마을을 포함하고 있음에도 불구하고 행정구 역별로 세부계획이 달라졌기 때문이다. 이에 따른 지역 내 이익분배의 불평등은 지역갈등의 원인이 되었다. 따 라서 앞으로의 생태관광계획은 광역적 차원에서 실제 대 상지 전체를 생태적 맥락, 사회적 맥락을 고려하여 계획 해야 할 것이다.

둘째, 사업의 진행과정에서 지역 환경에 대한 생태적 인 배려와 함께 중요하게 고려해야하는 것은 지역 내 이 익의 공평한 분배이다. 경제적 문제를 해결하지 않으면 주민참여 및 프로그램 활성화를 이루기 어렵다는 것이 다. 이를 위해서는 가능한 시설의 소규모 분산배치가 요 구된다. 물론 이와 함께 이용자의 불편을 최소화 하는 동선 배치, 시설물 공간배치도 함께 고려되어야 한다.

마지막으로 생태관광을 추진함에 있어서 주민교육과 프로그램 개발이 물리적 시설의 조성 못지않게 중요하 다. 시설지원 위주의 생태관광지 조성은 보상 및 지원에 대한 주민 간 차등을 야기하고 이는 갈등의 원인이 되고 있다. 또한 과도한 시설물 조성은 대상지의 생태환경이 나 정주환경을 훼손시킬 수도 있다. 따라서 생태관광 조 성 시에는 주민교육을 통한 생태관광에 대한 바른 인식 을 갖게 하고 생태관광에 관련된 프로그램 개발에 많은 투자를 해야 할 것이다.

본 연구는 우리나라의 생태관광 사업에 대한 진단적 성격을 가진다. 단, 본 연구에서는 예산 황새마을의 쟁점 에 집중한 나머지 $\mathrm{Q}$ 진술문들이 대리와 시목리 사이의 구체적인 갈등 현안에 집중되었다. 따라서 국내 생태관 광 추진에 대한 일반적인 갈등 양상을 파악하기 위해서 는 향후 다양한 생태관광 지역과의 비교 연구할 필요하 며, 이는 후속 연구로 남긴다.

주1) Q 방법론은 응답자( $\mathrm{P}$ 표본)들의 개인적인 특성이나 차이로부터 모집단(P집단)의 특성을 추론하는 것이 아니라 한 응답자가 $\mathrm{Q}$ 표본의 진술문들을 어떻게 구조화시키는가를 다루기 때문에 응답자인 P 표본의 선정이 확률적 표집방법을 따르지 않으며 표본수도 1 명에서 40 명 정도로 크지 않다는 특성을 갖는다. 단 사전에 더 많은 수의 모집단(P집단)을 인터뷰하여 정성적으로 분석한 후, 핵심 인물들을 소수로 선정하여 $\mathrm{Q}$ 요인분석을 실 시함으로서 대표성을 확보해야 한다(김순은, 2007 ; 김흥규, 2008). 


\section{References}

1. Cho, J. H., Kim, Y. G., 2008, Grounded Theoric Interpretation of Residents' Conflict Occurred in Process of Promoting a Rural Community Development Project: Focused on the Case of the Agricultural Experience Villages, Journal of Rural Planning 14(2): 1-12.

2. Chungcheong Today, 2012, Chungnam, Preparing Budget without any Plan, December 4th, on 2012(충 청투데이, 2012, 충남도, 황새마을사업 주먹구구 예 산편성, 2012년 12월 4일자).

3. Coles, T., 2009, "Ecotourism, NGOs and Development. A Critical Analysis." Current Issues in Tourism 12(3): 295-296.

4. García-Melón, M., et al., 2012, "A Combined ANP-delphi Approach to Evaluate Sustainable Tourism." Environmental Impact Assessment Review 34: 41-50.

5. Graci, S., 2013, "Collaboration and Partnership Development for Sustainable Tourism." Tourism Geographies 15(1): 25-42.

6. Gurung, D. B. and R. W. Scholz, 2008, "Community-based Ecotourism in Bhutan: Expert Evaluation of Stakeholder-based Scenarios." The International Journal of Sustainable Development \& World Ecology 15(5): 397-411.

7. Hunter, W. C., 2013, "Understanding Resident Subjectivities toward Tourism Using Q method: Orchid Island, Taiwan." Journal of Sustainable Tourism 21(2): 331-354.

8. Jungdo Ilbo, 2014, Yes or No about Yesan Stork Eco-village Development, June 10th on 2014(중도일 보, 2014, 예산 황새마을 조성 '찬반 팽팽', 2014년 6월 10일자).

9. Kim, H. G., 2008, Q Methodology(Philosophy of Science, Theory, Analysis and Application), Communication Books : Seoul, Korea (김흥규, 2008, $\mathrm{Q}$ 방법론 (과학철학, 이론, 분석 그리고 적용), 커 뮤니케이션북스 : 서울).

10. Kim, J., Ko D. W., 2011, A Change in Tourism Environmental Attitudes through Ecotourism Activities -Focusing on Ecotourism Participants in Upo Wetland-, Journal of Korea Institute of Landscape Architecture 39(1) : 54-65.
11. Kim, J. M., 2012, A Research on Consumer Preference for a Forest based Korean Medical Healing Tourism Product , Korea Journal of Environmental and Ecology 26(3) : 463-471.

12. Kim, S. E., 2010, Theory and Philosophy of the Q Methodology, Korea Social and Administrative Studies 20(4) : $1-25$.

13. Kim, S. E., 2007, Q Method \& Sociology, Gold Well Publishing Inc. : Seoul, Korea

14. Korean Research Institute for Humen Settlement, 2010, Conflict Management in Spatial Development Project ; Exploring People's Conception and Finding Policy Application. Korean Research Institute for Humen Settlement : Anyang.

15. Kyunghyang Shinmun, 2013, Stork-village which Attack Storks, July 25th on 2013 (경향신문, 2013, 황새잡는 황새마을. 2013년 7월 25일자).

16. Lee, H. Y., Oh, C. H., 2012, A Study on Visitors' Characteristics and Cognition in regard to Damage of Nature Environment in Different Types of Ecotourism Destination, Korea Journal of Environmental and Ecology 26(2) : 264-272.

17. Lee, J. H, Lee, H. Y., 2012, A Study on the Development of the Indicator Sets for Evaluating the Sustainable Eco-tourism and it's Application, Journal of Korean Geographical Society 47(6) : 853-869.

18. Lee, J. H., Son, Y. H., 2013, Current Status and Challenges of Planned Eco- tourism: Q Methodology and AHP Analysis for Stakeholders' Response, Focusing on Maha eco-tourism site in Pyeongchang-gun where 2018 Olympic \& Paralympic Winter Games will be held, SPSD conference.

19. Lee, S. J., Park, H. S., 2011, Views of the Related People toward the Construction of Garolim Tidal Power Plant, Studies of Local Administration, 25(2) : 271-301 (이순자, 박형서, 2011, Q 방법론을 활용한 갈등행위자 인식유형 및 특성에 관한 연구: 가로림 조력발전소 건설계획을 중심으로, 지방행정연구, 25(2) : 271-301.)

20. Russell C. Hurd \& Steven R. Brown, 2004, The Future of the Q Methodology Movement, Operant Subjectivity 28(1/2) : 58-96.

21. White, N. E., et al., 2013, "Complex Interrelationships between Ecotourism and Indigenous Peoples." in R Ballantyne \& J Packer (eds), 
International Handbook on Ecotourism, Edward Elgar Publishing : Cheltenham, UK.

22. Wunder, S., 2000, "Ecotourism and Economic Incentives - an Empirical approach." Ecological Economics 32(3): 465-479.

23. Yesangun, 2012, Regional Plan of Stork Village in Yesan, Chungcheongnamdo, Yesangun : Yesan, Korea (예산군, 2012, 충청남도 예산군 황새 권역단위 종 합정비사업 기본계획서, 예산군 : 예산).

24. YTN, 2012, Where is stork Restoration Project going.
March 31th on 2012(YTN, 2012, 황새 복원 사업은 어디로, 2012년 3월 31일자).

- $\quad$ Received 31 October 2014

- First Revised 4 November 2014

- Finally Revised 13 November 2014

- Accepted 13 November 2014 
